ISSN electrónico: 2602-8069

\title{
LA INVESTIGACIÓN DEL TURISMO COMUNITARIO EN EL SUR GLOBAL: UN ANÁLISIS CRÍTICO DE LA LITERATURA
}

Research on community-based tourism in the Global South: a critical analysis of the scientific literature

\author{
Verónica Santafé Troncoso \\ University of Saskatchewan \\ veronica.santafe@usask.ca \\ Ximena Aguirre Ulloa \\ Universidad Tecnológica Equinoccial \\ xaguirre@ute.edu.ec \\ Gabriela Alvarez Calupiña \\ Universidad de las Fuerzas Armadas ESPE - Ecuador \\ gfalvarez2@espe.edu.ec
}

Fecha de recepción del artículo: 23/03/2019

Fecha de aceptación definitiva: 11/06/2019 


\section{RESUMEN}

¿Quién ha investigado el desarrollo del turismo comunitario? y ¿cómo la dinámica metodológica de estas investigaciones ha contribuido a reducir la brecha de "injusticia cognitiva" entre Norte y Sur, en el contexto del conocimiento sobre turismo comunitario? son las interrogantes que guían el presente estudio. Para responderlas, se utilizan herramientas cuantitativas y cualitativas como instrumentos de análisis de la producción académica en este tema entre los años 2000 y 2015. Durante este período, la industria turística incursionó en la cooperación internacional y promovió iniciativas para el alivio de la pobreza, especialmente en países del Sur Global. Este período también representa la emergencia de perspectivas críticas en los estudios de turismo que cuestionan la real contribución de la industria turística para el alivio de la pobreza. Estas perspectivas principalmente cuestionan la exclusiva aplicación de enfoques económicos para entender los impactos multidimensionales de la industria turística en las comunidades anfitrionas, así como el escaso nivel de participación de las comunidades en la gestión del desarrollo turístico en sus territorios. Los resultados de esta investigación evidencian que la producción y difusión del conocimiento sobre turismo comunitario está concentradas en los países del Norte Global, situación que impide el acceso a este conocimiento por parte de investigadores locales, de las comunidades anfitrionas, y de los hacedores de políticas públicas. A nivel metodológico, se identificó que quienes investigan el turismo comunitario están interesados en desarrollar estudios que van más allá de la naturaleza económica del turismo, y buscan aplicar enfoques de investigación cualitativos y mixtos. Sin embargo, fueron muy pocos los autores de los artículos revisados que describen cómo sus valores y modos de ver el mundo influyen en el diseño de la investigación e interpretación de los datos.

Palabras clave: turismo comunitario; América Latina; métodos cualitativos; justicia cognitiva; Sur Global

\section{ABSTRACT}

Who has studied the development of community-based tourism? and how their methodological approaches have contributed to reducing the cognitive injustice between North and South, in the context of tourism and development studies? are the research questions that lead this study. To answer these questions, a mixed methods approach was applied to analyze the scientific contribution done between 2000 and 2015. During this period, the tourism industry started its work on international cooperation and poverty alleviation, especially in the Global South. This period also means the emergence of critical perspectives that pointed out the real contribution to reduce poverty done by the tourism industry. This critical approach also suggests the need to introduce more qualitative and mixed methods, as well as participatory approaches, to understand the real impacts attributed to the tourism industry. This research found that the scientific knowledge produced on the topic of communitybased tourism in the Global South is framed by uneven power relations between the Global North and South. These unequal relations make difficult the access to scientific knowledge by host communities, policymakers, and local researchers. This research also found that researchers on community-based tourism are looking for more comprehensive methodological approaches by applying qualitative and mixed research methods. However, the content analysis of the selected articles showed a low level of reflexivity among the researchers.

Keywords: community-based tourism; Latin America; qualitative methods, cognitive justice, Global South 


\section{INTRODUCCIÓN}

En el año 2000, las Naciones Unidas estableció los Objetivos de Desarrollo del Milenio - ODM - como la hoja de ruta a seguir para el desarrollo de los países en el mundo. La eliminación de la pobreza fue uno de los principales desafíos que se propuso como parte de estos objetivos. La Organización Mundial del Turismo, que desde el año 2003 entró en el Sistema de las Naciones Unidas como agencia especializada de pleno derecho, asumió también tareas para la erradicación de la pobreza y lanzó la Iniciativa ST-EP en el 2002. La Iniciativa ST-EP que significa turismo sostenible a favor de la reducción de la pobreza (del inglés, Sustainable Tourism- Eliminating Poverty) busca reducir la pobreza en comunidades rurales de países del Sur Global mediante la generación de ingresos económicos a través de la industria turística. Un reciente informe de la OMT señala que América Latina y África han sido las principales regiones donde se ha enfocado la iniciativa ST-EP (UNWTO, 2017).

Aunque los proyectos de turismo en comunidades indígenas y campesinas han sido una de las recetas populares por parte de la cooperación internacional en estas regiones, varios académicos han sido críticos sobre la real contribución que el turismo ha hecho para reducir la pobreza en los países del Sur Global. El argumento principal de estos autores sostiene que la pobreza es multidimensional y que su reducción no solo depende de la creación de ingresos económicos (Cañada y Gascón 2007; Spenceley y Meyer, 2012). Además, varios autores consideran que ciertas dinámicas de la industria turística están generando conflictos sociales y ambientales y, por ende, más pobreza entre comunidades que históricamente han sido marginalizadas (Gössling, 2005; Jamal y Camargo, 2014; Gascón y Ojeda, 2014; Gascón, 2015). Se considera también que incluir a la industria turística como parte de las agendas de cooperación y desarrollo representa un riesgo para las comunidades más vulnerables, ya que se vuelve más fácil el ingreso de capitales transnacionales que justifican la explotación de comunidades y su medio por un supuesto bienestar económico al cual las comunidades anfitrionas tienen mínimo o nulo acceso (Cañada y Gascón 2007; Mowforth y Munt, 2015).

El turismo comunitario ha sido el principal concepto para la promoción del desarrollo del turismo en comunidades indígenas y campesinas, especialmente en las últimas dos décadas. Esta tendencia ha captado también el interés de los académicos que cada vez más estudian el desarrollo del turismo comunitario, como se puede evidenciar en la Figura 1. Para varios autores, la popularidad del turismo comunitario no solo responde a recetas de desarrollo prescritas por agentes externos, sino que también responde a estrategias políticas y de reivindicación social por parte de las comunidades anfitrionas (Ruiz-Ballesteros, Hernández, Coca, Cantero y del Campo, 2008). El contenido político de este concepto puede evidenciarse claramente en la definición propuesta por la Federación Plurinacional de Turismo Comunitario del Ecuador: "El turismo comunitario es toda actividad turística solidaria con participación comunitaria desde una perspectiva intercultural, manejo adecuado del patrimonio natural y valoración del patrimonio cultural, con equidad en la distribución de los beneficios locales" (FEPTCE, 2007). Aunque a primera vista el turismo comunitario pueda ser una herramienta idónea para el alivio de la pobreza y el desarrollo sostenible de una comunidad, consideran que turismo y comunidad son dos sistemas que, al interactuar, pueden entrar en conflicto ya que son sistemas que funcionan bajo lógicas totalmente distintas. 
Figura 1. Artículos científicos producidos sobre el tema de turismo comunitario entre los años 2000 a 2015. Artículos científicos producidos entre los años 2000 a 2015 que se encuentran accesibles a través de la base de datos Scopus. Resultados obtenidos mediante la combinación de las palabras claves: "turismo comunitario" or "community based tourism"

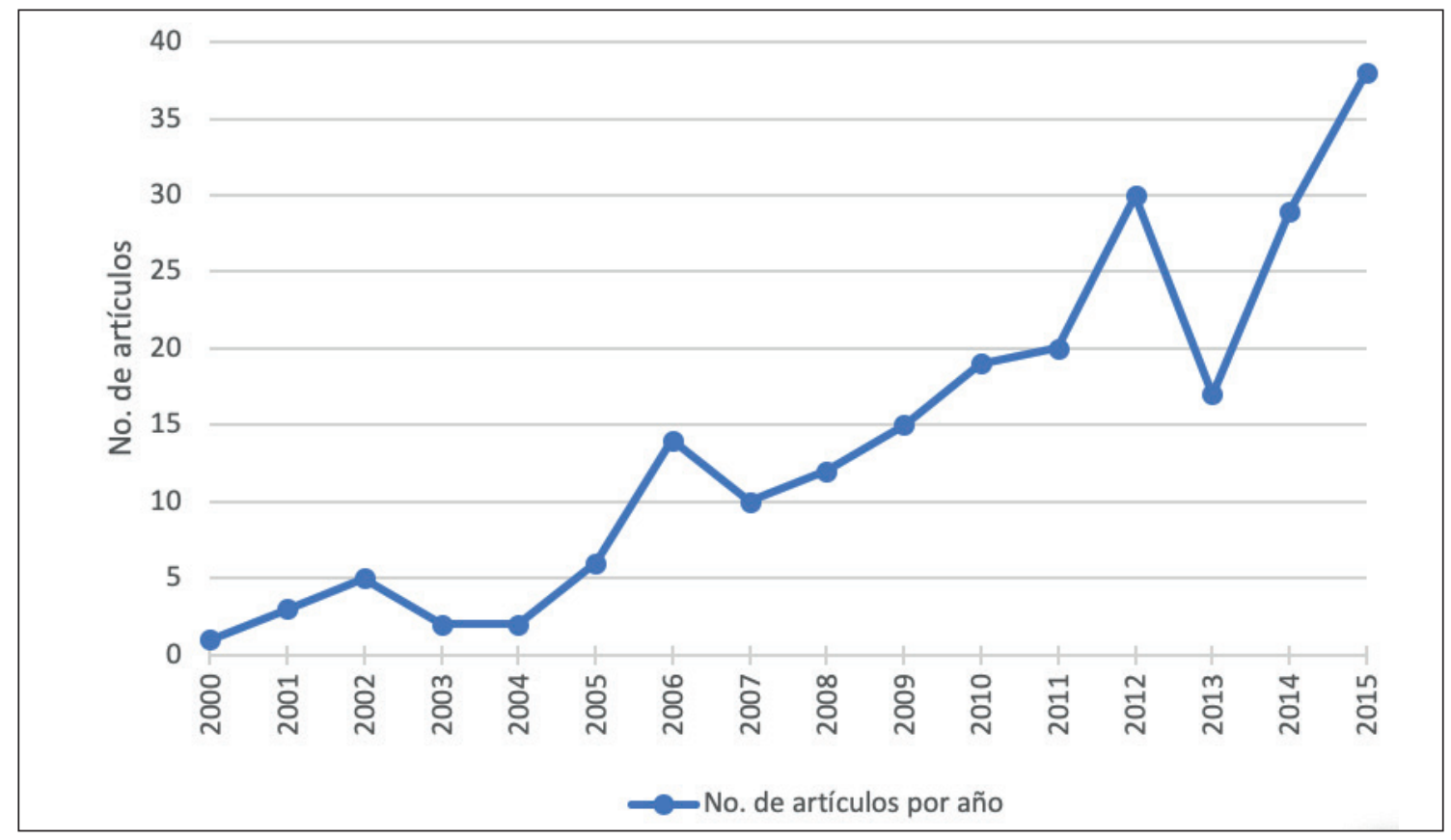

Fuente: Herramienta bibliométrica de la base de datos Scopus.

Los múltiples significados y la complejidad que implica la relación entre turismo y comunidad han creado una necesidad por metodologías de investigación que estudien esta relación de una manera más integral. Para responder a estos desafíos, cada vez son más los autores que promueven la aplicación de metodologías cualitativas y mixtas (cualitativas y cuantitativas) en el estudio del turismo (Goodson y Philimore, 2004; Torres y Ruiz-Ballesteros, 2009; Spenceley y Meyer, 2012). Este nuevo modo de hacer investigación sobre el desarrollo del turismo en comunidades indígenas y campesinas, especialmente del Sur Global, ha permitido evidenciar problemas de inequidad e injusticia en varios aspectos. Uno de estos aspectos es el modo en el que se produce y se distribuye la información científica generada sobre turismo y comunidad (Nielsen y Wilson, 2012; Carr, Ruhanen y Whitford, 2016).

Parafraseando a de Sousa Santos (2011) la pobreza e injusticia social en el Sur Global están atravesadas por una radical "injusticia cognitiva", la misma que implica un proyecto colonizador que destruye las formas heterogéneas de pensamiento, y que coloca al Norte como protagonista y hacedor de un único conocimiento, mientras que el Sur es un consumidor pasivo del mismo. De manera similar, Fraser (2005) considera que la injustica social está vinculada a la falta de reconocimiento de las identidades culturales y sus capacidades, y la falta de representación en los procesos de generación de conocimientos y toma de decisiones.

En un análisis de las brechas de conocimiento sobre turismo, entre Norte y Sur, Kobasi señala que la producción del conocimiento se produce y concentra en manos de la academia del Norte Global; conocimiento que, aunque muchas veces es hecho sobre temas 
y casos del Sur Global, se vuelve inaccesible por barreras económicas o idiomáticas (citado en Tribe, 2004, p. 56). A nivel específico de comunidades indígenas, Nielsen y Wilson (2012) describen como los estudios de turismo en estos contextos han entregado un papel pasivo a las comunidades anfitrionas y les han tratado como meros objetos de investigación, dejando de lado sus voces y conocimientos.

La complejidad en la relación entre turismo y comunidad, y la evidencia de una "injusticia cognitiva" que afecta, especialmente a las comunidades anfitrionas del Sur Global han creado la necesidad de pensar en un rol más crítico y reflexivo por parte de quienes desarrollan investigaciones sobre turismo comunitario. Varios autores consideran necesario que los investigadores evidencien como sus valores, cultura y modos de ver el mundo pueden influir en el diseño de la investigación y la interpretación de los datos, con la inclusión de estrategias metodológicas para reducir estas subjetividades (Goodson y Philimore, 2004; Datta et al., 2015).

El presente estudio se enfoca en los estudios del turismo comunitario en el contexto del Sur Global en general, y de América Latina en específico. El argumento que guía esta investigación es que la dinámica de las investigaciones sobre turismo comunitario ha contribuido en poco para cerrar la brecha de "injusticia cognitiva" entre Norte y Sur, en el contexto de los estudios de turismo y desarrollo. En una primera parte, se exploran cuatro variables que nos permiten tener una idea básica de quienes y desde donde han estudiado el turismo comunitario: el país de afiliación del investigador principal, su área de estudio, el idioma de publicación del artículo científico, y el tipo de acceso para la descarga del artículo científico desde la base de datos. En una segunda parte, el estudio se concentra específicamente en el caso de América Latina, y se identifica una muestra de estudios científicos sobre turismo comunitario realizados en la región para, mediante un análisis del contenido, analizar sus estrategias metodológicas. El objetivo de esta segunda parte es explorar los diseños de investigación y determinar cómo los autores asumen los retos metodológicos y teóricos que representa realizar investigaciones sobre turismo en comunidades indígenas y campesinas en el contexto del Sur Global.

Los resultados de este estudio permitirán evidenciar si las investigaciones sobre turismo comunitario durante los años 2000 y 2015, que es conocida como la época de la promoción del turismo como una herramienta para aliviar la pobreza en los países del Sur Global, han contribuido a cerrar la brecha de "injusticia cognitiva" que afecta a las comunidades indígenas y campesinas que trabajan en el turismo, y si han promovido un pensamiento crítico y reflexivo entre los investigadores.

\section{MATERIALES Y MÉTODOS}

Para responder a las preguntas planteadas en este estudio se desarrolló un análisis bibliométrico y de contenido mediante la utilización de herramientas cualitativas y cuantitativas de investigación. Para responder a la primera pregunta de investigación, relacionada con el perfil básico de las investigaciones hechas en turismo comunitario, se utilizaron las herramientas de análisis bibliométrico de la base de datos Scopus. Las palabras claves utilizadas para la búsqueda fueron ("community-based tourism" OR "turismo comunitario"). Además, se aplicó un filtro con el rango de tiempo para el análisis que fue del año 2000 al año 2015. El resultado final de esta búsqueda fueron 223 artículos identificados. Luego, se procedió a analizar de manera global los resultados obtenidos en cuanto al país de afiliación del autor principal, el área de estudio, el idioma en el cual está publicado el artículo, y el tipo 
de acceso requerido para la descarga de los artículos. Los resultados de esta primera fase son considerados para un contexto global.

Para responder a la segunda pregunta, relacionada con el cómo se ha investigado el turismo comunitario, se procedió a un análisis más específico. Se tomó el caso de América Latina y se procedió a identificar una muestra representativa de artículos científicos que cumplan con los siguientes criterios: artículos científicos publicados y accesibles a través de las bases de datos SCOPUS o Google Scholar, que utilicen metodologías cualitativas o mixtas de investigación, y que hayan sido publicados entre los años 2000 y 2015 . Se identificaron 21 artículos científicos que cumplieron con todos estos criterios. Para el análisis del contenido de estos artículos se utilizaron las herramientas de análisis de contenido del software NVIVO. Mediante este programa se identificaron los temas más relevantes para responder a la interrogante de investigación.

\section{RESULTADOS}

\section{Perfil básico de las investigaciones hechas en turismo comunitario durante el período 2000-2015}

Las herramientas bibliométricas de Scopus permitieron filtrar la información e identificar qué países concentran la mayor cantidad de producción científica en cuanto al estudio del turismo comunitario, las áreas de estudio que se utilizan particularmente para estudiar esta temática, los idiomas en los que se publican los resultados de estos estudios, y el tipo de acceso que estos artículos científicos tienen para su lectura y descarga. Estos datos en conjunto nos permiten conocer quiénes y desde dónde investigan el turismo comunitario en el Sur Global.

En cuanto al país de afiliación, la información de Scopus muestra que quienes investigan el turismo comunitario en el mundo, están principalmente afiliados a instituciones de investigación localizadas en países del Norte Global, llamados también países desarrollados. La Figura 2 muestra que los diez países que concentran la mayor cantidad de producción científica suman, en conjunto, un total de 182 artículos, que corresponden al $82 \%$ del total de los 223 artículos seleccionados. En general, se puede ver que los países protagonistas en la producción científica sobre turismo comunitario son Estados Unidos y Reino Unido. No tan lejos, están Australia, Canadá, España y Francia con un gran número de contribuciones. Se observa también una importante producción de conocimiento en Bostwana, Sudáfrica, Malasia y Tailandia que son considerados países en vías de desarrollo, o del Sur Global. Llama la atención que ningún país de América Latina aparece como un país protagonista en la producción de conocimiento sobre turismo comunitario.

Otro elemento importante del perfil de las investigaciones está relacionado con el área de estudio desde la cual el investigador aborda el turismo comunitario. La Figura 3 muestra las estadísticas de SCOPUS donde las Ciencias Sociales con el 40,9\% son la principal plataforma desde donde se ha investigado el turismo comunitario durante el período analizado, 2000-2015. Las Ciencias Administrativas representan la segunda plataforma con el $26 \%$. Otras áreas como las Ciencias Ambientales, Artes y Humanidades, Agricultura, Ingeniería, Energía y otras áreas emergentes también son reconocidas, aunque su peso no es comparable con el de las Ciencias Sociales. 
Figura 2. Los diez países con mayor número de publicaciones en el tema de turismo comunitario durante los años 2000-2015

\begin{tabular}{|c|c|c|c|}
\hline & \multirow{12}{*}{$\begin{array}{l}\text { No de publicaciones } \\
36\end{array}$} & País & $\begin{array}{c}\text { No de } \\
\text { publicaciones }\end{array}$ \\
\hline & & Estados Unidos & 36 \\
\hline & & Reino Unido & 27 \\
\hline ie & & Malasia & 22 \\
\hline & & Botswana & 20 \\
\hline & & Sudáfrica & 19 \\
\hline 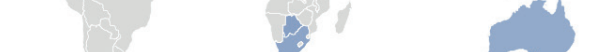 & & Australia & 18 \\
\hline \multirow{5}{*}{$\begin{array}{r}\text { Powered by Bing } \\
\text { O GeoNames, HERE, MSFT, Microsoft, Navinfo, Thinkware Extract, Wikipedia }\end{array}$} & & España & 11 \\
\hline & & Tailandia & 11 \\
\hline & & Canadá & 10 \\
\hline & & Francia & 8 \\
\hline & & TOTAL & 182 \\
\hline
\end{tabular}

Fuente: Base de datos Scopus.

Figura 3. Principales áreas de estudio utilizadas en la investigación del turismo comunitario durante los años 2000-2015

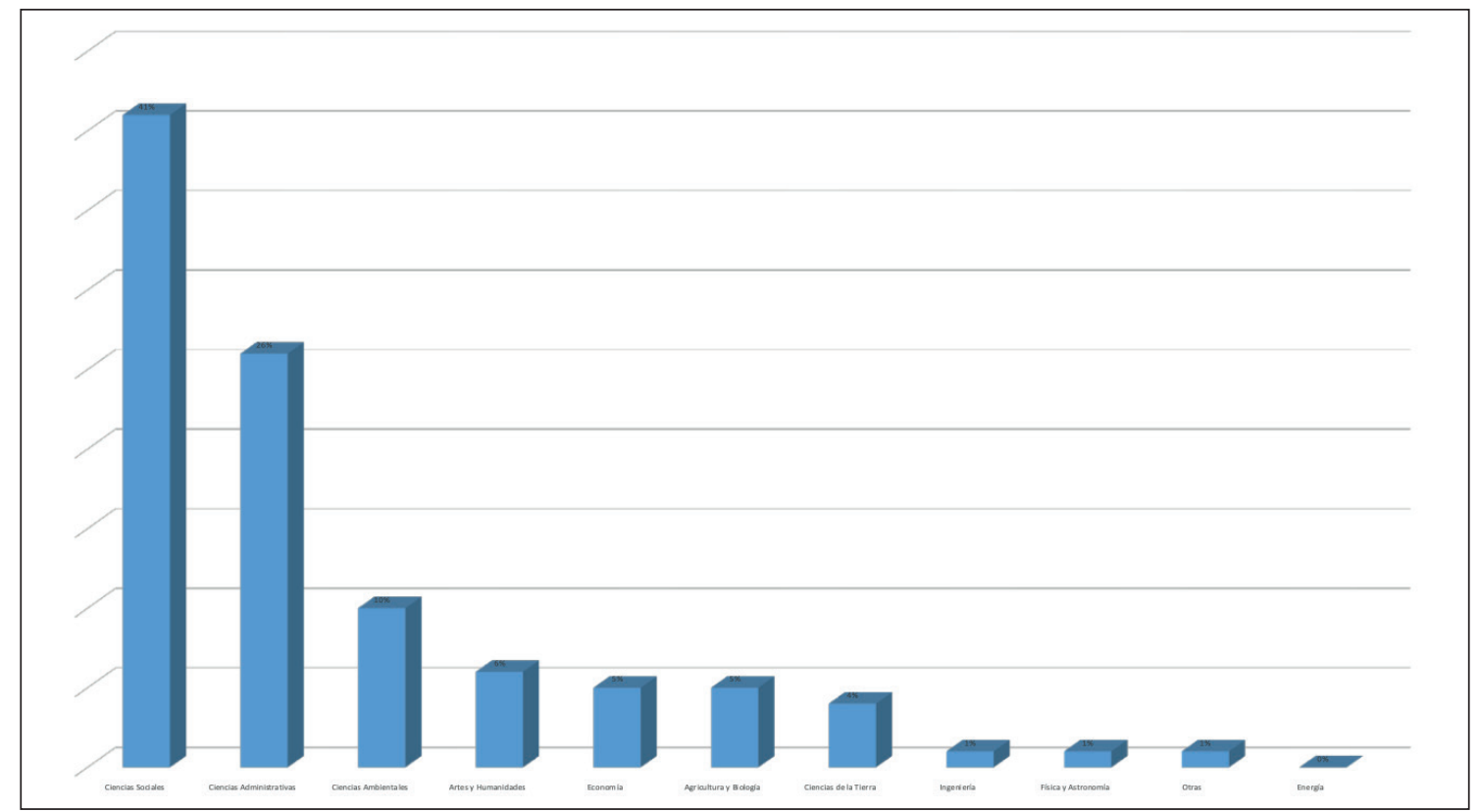

Fuente: Base de datos Scopus.

La Figura 4 muestra el idioma de publicación de los artículos analizados. El idioma inglés con 212 artículos, que representan el $95 \%$ de los 223 artículos seleccionados para este análisis, es el idioma que predomina en la divulgación del conocimiento científico so- 
bre turismo comunitario. El español, el francés, el alemán, y el mandarín representan en conjunto apenas un $5 \%$ de los artículos publicados. Estos resultados tienen relación con la información presentada en la Figura 2 en referencia a los países donde se concentra la producción del conocimiento sobre turismo comunitario, ya que el idioma ingles es el idioma oficial en seis de estos diez países.

Figura 4. El idioma de publicación de los artículos científicos que reportan estudios de turismo comunitario entre los años 2000 y 2015

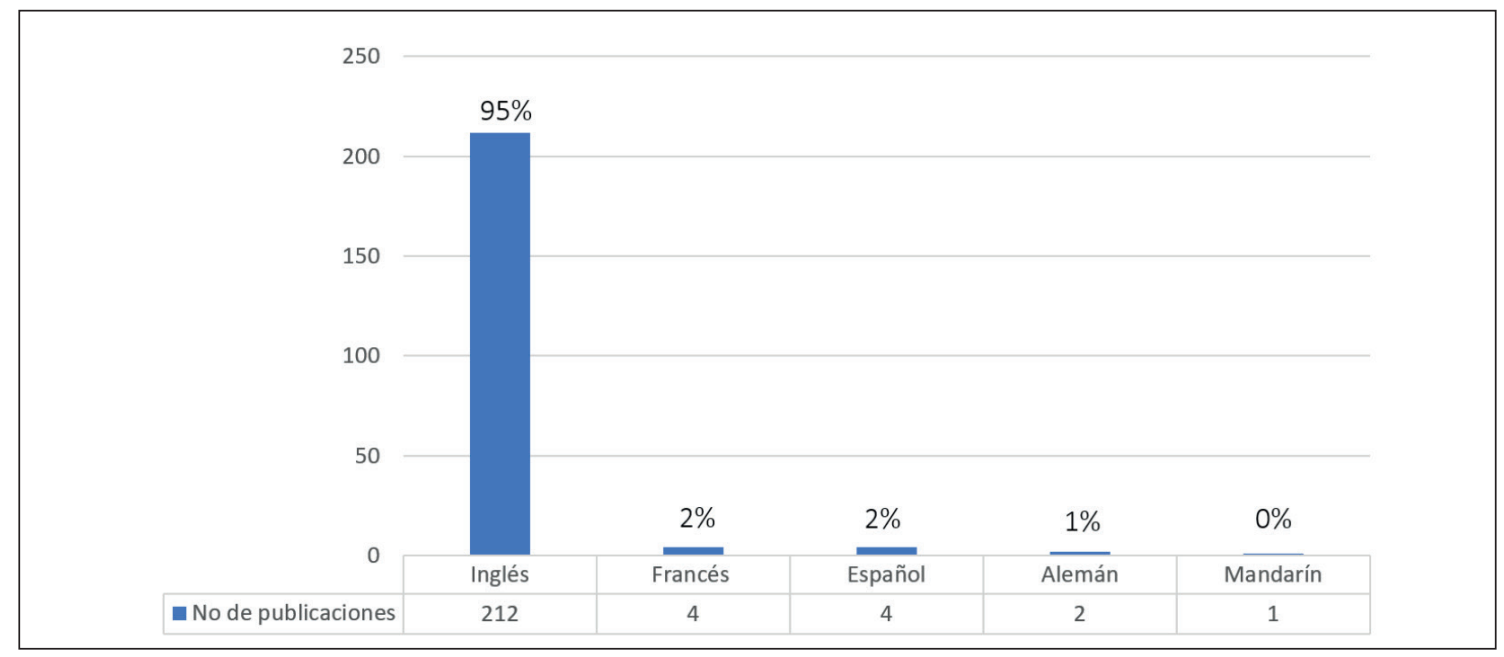

Fuente: Base de datos Scopus. En el caso del idioma mandarin aparece como $0 \%$ debido a la contribución es menos del $0,5 \%$ y el formato utilizado en Excel, lo coloca como $0 \%$.

La Figura 5 muestra el tipo de acceso que los 223 artículos tienen en la base de datos de Scopus. 205 artículos, que representan el $92 \%$ de los artículos analizados, requieren una suscripción o pago para su acceso y descarga. Y, apenas 18 artículos, que representan el 8 $\%$, son accesibles de manera libre y gratuita.

Figura 5. Tipo de acceso de los artículos científicos que reportan estudios de turismo comunitario entre los años 2000 y 2015.
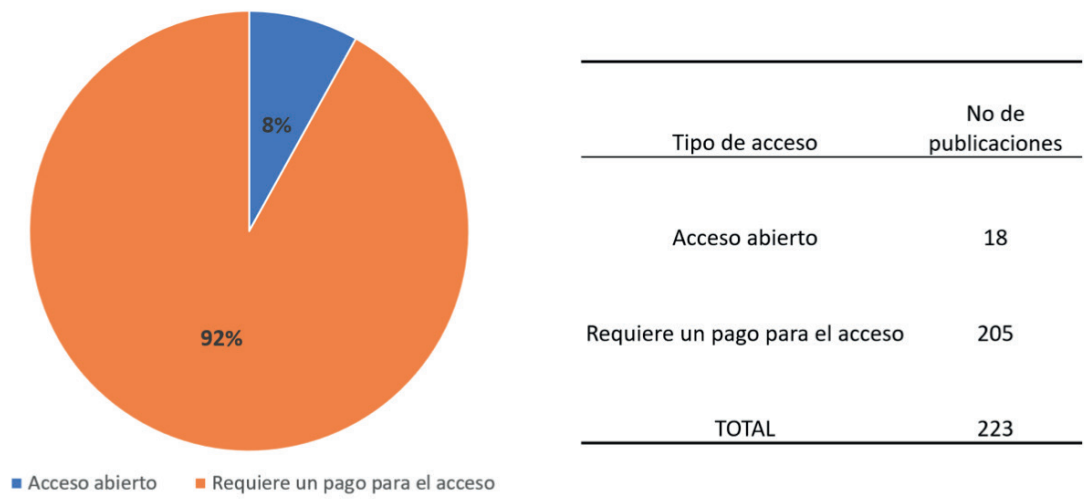

Fuente: Base de datos Scopus. 


\section{Dinámica de las investigaciones sobre turismo comunitario}

A continuación, se presenta el análisis del contenido de los 21 artículos científicos que reportan investigaciones sobre turismo comunitario en América Latina. El enfoque principal de este análisis es el diseño de las investigaciones, para ello se toma como referencia las recomendaciones de Hays y Singh (2012) en cuanto al diseño de investigación. La Tabla 1 resume la información básica de los artículos con los datos de autoría, titulo, año de publicación, idioma en el que está publicado el artículo, el país de afiliación del primer autor, y el país donde se aplica la investigación. Además, se incluyen el paradigma de investigación, la tradición de investigación, y los métodos de recolección de información.

\section{Tabla 1}

Resumen de los 21 artículos seleccionados para el análisis de los diseños de investigación aplicados al estudio del turismo comunitario en el contexto de América Latina durante los años 2000-2015.

\begin{tabular}{|c|c|c|c|c|c|c|c|c|c|}
\hline & Autores & Título & $\begin{array}{l}\text { Año de } \\
\text { publi- } \\
\text { cación }\end{array}$ & $\begin{array}{l}\text { Idio- } \\
\text { ma }\end{array}$ & $\begin{array}{l}\text { País de } \\
\text { afiliación } \\
\text { del autor }\end{array}$ & $\begin{array}{c}\text { País } \\
\text { del } \\
\text { estudio }\end{array}$ & $\begin{array}{l}\text { Paradig- } \\
\text { ma de } \\
\text { investi- } \\
\text { gación }\end{array}$ & $\begin{array}{l}\text { Tradición } \\
\text { de investi- } \\
\text { gación }\end{array}$ & $\begin{array}{l}\text { Método de } \\
\text { recolección de } \\
\text { información }\end{array}$ \\
\hline 1 & $\begin{array}{l}\text { Brenner, } \\
\text { L., del Río, } \\
\text { D. V. }\end{array}$ & $\begin{array}{l}\text { Community- } \\
\text { based } \\
\text { ecotourism and } \\
\text { environmental } \\
\text { protection in } \\
\text { Mexico: A syner- } \\
\text { getic strategy or } \\
\text { trendy slogan? }\end{array}$ & 2013 & IN & México & México & $\begin{array}{l}\text { No se } \\
\text { evidencia }\end{array}$ & $\begin{array}{l}\text { Estudio de } \\
\text { caso }\end{array}$ & $\begin{array}{l}\text { Entrevistas de } \\
\text { observación no } \\
\text { participante, } \\
\text { análisis histórico } \\
\text { de la organi- } \\
\text { zación social, } \\
\text { encuestas }\end{array}$ \\
\hline 2 & $\begin{array}{l}\text { Carpentier, } \\
\text { Julie }\end{array}$ & $\begin{array}{l}\text { Los Achuar y } \\
\text { el ecoturismo: } \\
\text { una estrategia } \\
\text { sostenible para } \\
\text { un desarrollo } \\
\text { autónomo }\end{array}$ & 2014 & ES & Francia & Ecuador & $\begin{array}{l}\text { No se } \\
\text { evidencia }\end{array}$ & $\begin{array}{l}\text { Estudio de } \\
\text { caso }\end{array}$ & Entrevistas \\
\hline 3 & $\begin{array}{l}\text { Duffy, L. N., } \\
\text { Mowatt, R. } \\
\text { A., Cnace- } \\
\text { llor, C. H., } \\
\text { Cárdenas }\end{array}$ & $\begin{array}{l}\text { Machismo- } \\
\text { Marianismo and } \\
\text { the Involvement } \\
\text { of Women in } \\
\text { a Community- } \\
\text { Based Tourism } \\
\text { Project in } \\
\text { Ecuador, South } \\
\text { America }\end{array}$ & 2012 & IN & $\begin{array}{l}\text { Estados } \\
\text { Unidos }\end{array}$ & Ecuador & Feminismo & $\begin{array}{l}\text { Investiga- } \\
\text { ción social } \\
\text { comunitaria }\end{array}$ & $\begin{array}{l}\text { Grupos focales, } \\
\text { observación par- } \\
\text { ticipante, diario } \\
\text { de campo }\end{array}$ \\
\hline 4 & $\begin{array}{l}\text { Falconi, F y } \\
\text { Ponce, J. }\end{array}$ & $\begin{array}{l}\text { Ecoturismo: } \\
\text { empredimientos } \\
\text { populares como } \\
\text { alternativa a } \\
\text { un desarrollo } \\
\text { excluyente }\end{array}$ & 2006 & ES & Ecuador & Ecuador & $\begin{array}{l}\text { No se } \\
\text { evidencia }\end{array}$ & $\begin{array}{l}\text { Estudio } \\
\text { de caso } \\
\text { - análisis } \\
\text { compara- } \\
\text { tivo }\end{array}$ & $\begin{array}{l}\text { Encuesta, en- } \\
\text { trevistas, grupos } \\
\text { focales }\end{array}$ \\
\hline 5 & Gascón J & $\begin{array}{l}\text { Community- } \\
\text { based tourism } \\
\text { and peasant } \\
\text { differentiation. } \\
\text { Considerations } \\
\text { from an andean } \\
\text { case }\end{array}$ & 2011 & IN & España & Perú & $\begin{array}{l}\text { No se } \\
\text { evidencia }\end{array}$ & $\begin{array}{l}\text { Estudio de } \\
\text { caso }\end{array}$ & Entrevistas \\
\hline
\end{tabular}


Santafé-Troncoso, Verónica Tatiana - Aguirre-Ulloa, Luz Ximena - Álvarez- Calupiña, Gabriela Fernanda

LA INVESTIGACIÓN DEL TURISMO COMUNITARIO EN EL SUR GLOBAL:

UN ANÁLISIS CRÍTICO DE LA LITERATURA

\begin{tabular}{|c|c|c|c|c|c|c|c|c|c|}
\hline & Autores & Título & $\begin{array}{l}\text { Año de } \\
\text { publi- } \\
\text { cación }\end{array}$ & $\begin{array}{l}\text { Idio- } \\
\text { ma }\end{array}$ & $\begin{array}{l}\text { País de } \\
\text { afiliación } \\
\text { del autor }\end{array}$ & $\begin{array}{c}\text { País } \\
\text { del } \\
\text { estudio }\end{array}$ & $\begin{array}{l}\text { Paradig- } \\
\text { ma de } \\
\text { investi- } \\
\text { gación }\end{array}$ & $\begin{array}{c}\text { Tradición } \\
\text { de investi- } \\
\text { gación }\end{array}$ & $\begin{array}{l}\text { Método de } \\
\text { recolección de } \\
\text { información }\end{array}$ \\
\hline 6 & Gascón J & $\begin{array}{l}\text { The limitations } \\
\text { of community- } \\
\text { based tourism } \\
\text { as an instrument } \\
\text { of development } \\
\text { cooperation: } \\
\text { the value of the } \\
\text { Social Vocation } \\
\text { of the Territory } \\
\text { concept }\end{array}$ & 2013 & ES & España & Perú & $\begin{array}{l}\text { Construc- } \\
\text { tivismo } \\
\text { social }\end{array}$ & $\begin{array}{l}\text { Estudio de } \\
\text { caso }\end{array}$ & $\begin{array}{l}\text { Análisis } \\
\text { estructural }\end{array}$ \\
\hline 7 & Kuo Erin & $\begin{array}{l}\text { Community } \\
\text { Impacts of } \\
\text { Ecotourism: A } \\
\text { Case-study of a } \\
\text { Women's Arti- } \\
\text { san Cooperative } \\
\text { in Monteverde, } \\
\text { Costa Rica }\end{array}$ & 2008 & IN & $\begin{array}{l}\text { Estados } \\
\text { Unidos }\end{array}$ & $\begin{array}{l}\text { Costa } \\
\text { Rica }\end{array}$ & $\begin{array}{l}\text { No se } \\
\text { evidencia }\end{array}$ & $\begin{array}{l}\text { Estudio de } \\
\text { caso }\end{array}$ & Encuesta \\
\hline 8 & $\begin{array}{l}\text { Lupoli, C. } \\
\text { Al y Morse, } \\
\text { W.C. }\end{array}$ & $\begin{array}{l}\text { Assessing } \\
\text { the impacts } \\
\text { of internatio- } \\
\text { nal volunteer } \\
\text { tourism in host } \\
\text { communities: A } \\
\text { new approach } \\
\text { to organizing } \\
\text { and prioritizing } \\
\text { indicators }\end{array}$ & 2014 & IN & $\begin{array}{l}\text { Estados } \\
\text { Unidos }\end{array}$ & Ecuador & $\begin{array}{l}\text { Construc- } \\
\text { tivismo } \\
\text { social }\end{array}$ & $\begin{array}{l}\text { fenomeno- } \\
\text { logía }\end{array}$ & Encuesta online \\
\hline 9 & $\begin{array}{l}\text { Lupoli, C. } \\
\text { A., Morse, } \\
\text { W. C. Bailey, } \\
\text { C., Schel- } \\
\text { has, J. }\end{array}$ & $\begin{array}{l}\text { Indicator } \\
\text { development } \\
\text { methodology } \\
\text { for volunteer } \\
\text { tourism in host } \\
\text { communities: } \\
\text { creating a } \\
\text { low-cost, locally } \\
\text { applicable, rapid } \\
\text { assessment tool }\end{array}$ & 2015 & IN & $\begin{array}{l}\text { Estados } \\
\text { Unidos }\end{array}$ & Ecuador & $\begin{array}{l}\text { Construc- } \\
\text { tivismo } \\
\text { social }\end{array}$ & $\begin{array}{l}\text { Multiples } \\
\text { estudios de } \\
\text { caso }\end{array}$ & Grupos focales \\
\hline 10 & Lyall Angus & $\begin{array}{l}\text { Estado y turis- } \\
\text { mo comunitario } \\
\text { en la sierra } \\
\text { central. }\end{array}$ & 2011 & ES & $\begin{array}{l}\text { Estados } \\
\text { Unidos }\end{array}$ & Ecuador & $\begin{array}{l}\text { No se } \\
\text { evidencia }\end{array}$ & Etnografía & $\begin{array}{l}\text { Observación } \\
\text { participante }\end{array}$ \\
\hline 11 & $\begin{array}{l}\text { Matarrita- } \\
\text { Cascante, } \\
\text { D., Brennan, } \\
\text { M.A., Luloff, } \\
\text { A.E. }\end{array}$ & $\begin{array}{l}\text { Community } \\
\text { agency and sus- } \\
\text { tainable tourism } \\
\text { development: } \\
\text { The case of La } \\
\text { Fortuna, Costa } \\
\text { Rica }\end{array}$ & 2010 & IN & $\begin{array}{l}\text { Estados } \\
\text { Unidos }\end{array}$ & $\begin{array}{l}\text { Costa } \\
\text { Rica }\end{array}$ & $\begin{array}{l}\text { No se } \\
\text { evidencia }\end{array}$ & $\begin{array}{l}\text { Estudio de } \\
\text { caso }\end{array}$ & $\begin{array}{l}\text { Entrevista, } \\
\text { observación } \\
\text { participante }\end{array}$ \\
\hline 12 & $\begin{array}{l}\text { Mitchell, } \\
\text { R.E., Ea- } \\
\text { gles, P.F.J. }\end{array}$ & $\begin{array}{l}\text { An integrative } \\
\text { approach to tou- } \\
\text { rism: Lessons } \\
\text { from the Andes } \\
\text { of Peru }\end{array}$ & 2001 & IN & Australia & Perú & $\begin{array}{l}\text { No se } \\
\text { evidencia }\end{array}$ & $\begin{array}{l}\text { Estudio de } \\
\text { caso }\end{array}$ & $\begin{array}{l}\text { Encuesta, } \\
\text { entrevista, } \\
\text { observación par- } \\
\text { ticipante, diario } \\
\text { de campo }\end{array}$ \\
\hline 13 & $\begin{array}{l}\text { Mitchell, } \\
\text { R.E., Reid, } \\
\text { D.G. }\end{array}$ & $\begin{array}{l}\text { Community in- } \\
\text { tegration: Island } \\
\text { tourism in Peru }\end{array}$ & 2001 & IN & Australia & Perú & $\begin{array}{l}\text { No se } \\
\text { evidencia }\end{array}$ & $\begin{array}{l}\text { Estudio de } \\
\text { caso }\end{array}$ & $\begin{array}{l}\text { Encuesta, } \\
\text { entrevista, } \\
\text { observación par- } \\
\text { ticipante, diario } \\
\text { de campo }\end{array}$ \\
\hline
\end{tabular}


LA INVESTIGACIÓN DEL TURISMO COMUNITARIO EN EL SUR GLOBAL:

UN ANÁLISIS CRÍTICO DE LA LITERATURA

\begin{tabular}{|c|c|c|c|c|c|c|c|c|c|}
\hline & Autores & Título & $\begin{array}{l}\text { Año de } \\
\text { publi- } \\
\text { cación }\end{array}$ & $\begin{array}{l}\text { Idio- } \\
\text { ma }\end{array}$ & $\begin{array}{l}\text { País de } \\
\text { afiliación } \\
\text { del autor }\end{array}$ & $\begin{array}{c}\text { País } \\
\text { del } \\
\text { estudio }\end{array}$ & $\begin{array}{l}\text { Paradig- } \\
\text { ma de } \\
\text { investi- } \\
\text { gación }\end{array}$ & $\begin{array}{c}\text { Tradición } \\
\text { de investi- } \\
\text { gación }\end{array}$ & $\begin{array}{l}\text { Método de } \\
\text { recolección de } \\
\text { información }\end{array}$ \\
\hline 14 & $\begin{array}{l}\text { Pereiro X y } \\
\text { C De Leon }\end{array}$ & $\begin{array}{l}\text { Los impactos } \\
\text { del turismo } \\
\text { en Kuna Yala } \\
\text { Panama }\end{array}$ & 2007 & ES & Portugal & Panamá & $\begin{array}{l}\text { Construc- } \\
\text { tivismo } \\
\text { social }\end{array}$ & Etnografía & $\begin{array}{l}\text { Etnografía } \\
\text { visual, observa- } \\
\text { ción participan- } \\
\text { te, entrevistas, } \\
\text { grupos focales, } \\
\text { historias de } \\
\text { vida. }\end{array}$ \\
\hline 15 & $\begin{array}{l}\text { Ruiz -Ba- } \\
\text { llesteros E. } \\
\text { y Gual, M. }\end{array}$ & $\begin{array}{l}\text { The Emer- } \\
\text { gence of New } \\
\text { Commons: } \\
\text { Community } \\
\text { and Multi-Level } \\
\text { Governance in } \\
\text { the Ecuadorian } \\
\text { Coast }\end{array}$ & 2012 & IN & España & Ecuador & $\begin{array}{l}\text { No se } \\
\text { evidencia }\end{array}$ & $\begin{array}{l}\text { Estudio de } \\
\text { caso-Etno- } \\
\text { grafía }\end{array}$ & $\begin{array}{l}\text { Observación } \\
\text { participante, } \\
\text { entrevista, } \\
\text { grupos focales, } \\
\text { encuestas. }\end{array}$ \\
\hline 16 & $\begin{array}{l}\text { Ruiz-Balles- } \\
\text { teros, E. }\end{array}$ & $\begin{array}{l}\text { Social-ecologi- } \\
\text { cal resilience } \\
\text { and community- } \\
\text { based tourism. } \\
\text { An approach } \\
\text { from Agua Blan- } \\
\text { ca, Ecuador. }\end{array}$ & 2011 & IN & España & Ecuador & $\begin{array}{l}\text { No se } \\
\text { evidencia }\end{array}$ & $\begin{array}{l}\text { Estudio de } \\
\text { caso-Etno- } \\
\text { grafía }\end{array}$ & $\begin{array}{l}\text { Observación } \\
\text { participante, } \\
\text { entrevista, } \\
\text { grupos focales, } \\
\text { encuestas. }\end{array}$ \\
\hline 17 & $\begin{array}{l}\text { Ruiz-Balles- } \\
\text { teros, E., } \\
\text { Hernandez, } \\
\text { M., Coca, } \\
\text { A., Cantero, } \\
\text { P., y del } \\
\text { Campo, A. }\end{array}$ & $\begin{array}{l}\text { Turismo } \\
\text { comunitario } \\
\text { en Ecuador. } \\
\text { Comprendiendo } \\
\text { el community- } \\
\text { based tourism } \\
\text { desde la } \\
\text { comunidad. }\end{array}$ & 2008 & ES & España & Ecuador & $\begin{array}{l}\text { No se } \\
\text { evidencia }\end{array}$ & $\begin{array}{l}\text { Estudio de } \\
\text { caso-Etno- } \\
\text { grafía }\end{array}$ & $\begin{array}{l}\text { Observación } \\
\text { participante, } \\
\text { entrevistas, his- } \\
\text { torias de vida }\end{array}$ \\
\hline 18 & $\begin{array}{l}\text { Ruiz-Balles- } \\
\text { teros, E., } \\
\text { Brondizio, } \\
\text { E. S. }\end{array}$ & $\begin{array}{l}\text { Building } \\
\text { negotiated } \\
\text { agreement: The } \\
\text { emergence of } \\
\text { community- } \\
\text { based tourism } \\
\text { in floreana } \\
\text { (Galápagos } \\
\text { Islands) }\end{array}$ & 2013 & IN & España & Ecuador & $\begin{array}{l}\text { No se } \\
\text { evidencia }\end{array}$ & $\begin{array}{l}\text { Etno- } \\
\text { grafía y } \\
\text { análisis del } \\
\text { discurso }\end{array}$ & $\begin{array}{l}\text { Observación } \\
\text { participante, } \\
\text { entrevistas, his- } \\
\text { torias de vida }\end{array}$ \\
\hline 19 & $\begin{array}{l}\text { Santafe } \\
\text { Verónica }\end{array}$ & $\begin{array}{l}\text { Turismo } \\
\text { comunitario e } \\
\text { interculturalidad. }\end{array}$ & 2013 & ES & Ecuador & Ecuador & $\begin{array}{l}\text { Teoría } \\
\text { crítica }\end{array}$ & $\begin{array}{l}\text { Estudio de } \\
\text { caso }\end{array}$ & $\begin{array}{l}\text { Entrevistas, } \\
\text { observaciones, } \\
\text { grupos focales, } \\
\text { mapas sociales. }\end{array}$ \\
\hline 20 & $\begin{array}{l}\text { Trejos, B., } \\
\text { Chiang, L.- } \\
\text { H. N. }\end{array}$ & $\begin{array}{l}\text { Local economic } \\
\text { linkages to } \\
\text { community- } \\
\text { based tourism in } \\
\text { rural Costa Rica }\end{array}$ & 2009 & IN & Taiwan & $\begin{array}{l}\text { Costa } \\
\text { Rica }\end{array}$ & $\begin{array}{l}\text { No se } \\
\text { evidencia }\end{array}$ & $\begin{array}{l}\text { Estudio de } \\
\text { caso }\end{array}$ & $\begin{array}{l}\text { Entrevistas, } \\
\text { observaciones, } \\
\text { diario de campo }\end{array}$ \\
\hline 21 & $\begin{array}{l}\text { Zapata, } \\
\text { M. J., } \\
\text { Hall, C. M., } \\
\text { Lindo, } \\
\text { P.,Vanders- } \\
\text { chaeghe, M. }\end{array}$ & $\begin{array}{l}\text { Can community- } \\
\text { based tourism } \\
\text { contribute to } \\
\text { development } \\
\text { and poverty } \\
\text { alleviation? } \\
\text { Lessons from } \\
\text { Nicaragua }\end{array}$ & 2011 & IN & $\begin{array}{l}\text { Suecia, } \\
\text { Nueva } \\
\text { Zelanda } \\
\text { Nica- } \\
\text { ragua, } \\
\text { Nicaragua }\end{array}$ & $\begin{array}{l}\text { Nicara- } \\
\text { gua }\end{array}$ & $\begin{array}{l}\text { No se } \\
\text { evidencia }\end{array}$ & $\begin{array}{l}\text { Estudio de } \\
\text { caso }\end{array}$ & $\begin{array}{l}\text { grupo focal, } \\
\text { encuestas, } \\
\text { observaciones. }\end{array}$ \\
\hline
\end{tabular}

Fuente: Elaborada por las autoras.

Nota: $E S=$ español, ING= inglés. 
Hays y Singh (2012) consideran que para desarrollar una investigación con enfoques cualitativos o mixtos es necesario incluir tres elementos clave: el paradigma de investigación, la tradición de investigación y los métodos para recopilar información. Para estas autoras, estos tres elementos están interconectados y deben ser coherentes entre sí, ya que en conjunto determinan el diseño de la investigación y el modo en que el investigador se relaciona con el objeto de estudio. La figura 6 resume el diseño de investigación utilizado en los 21 artículos en referencia a los tres elementos citados.

Figura 6. Los diseños de investigación del turismo comunitario en América Latina durante los años 2000-2015.

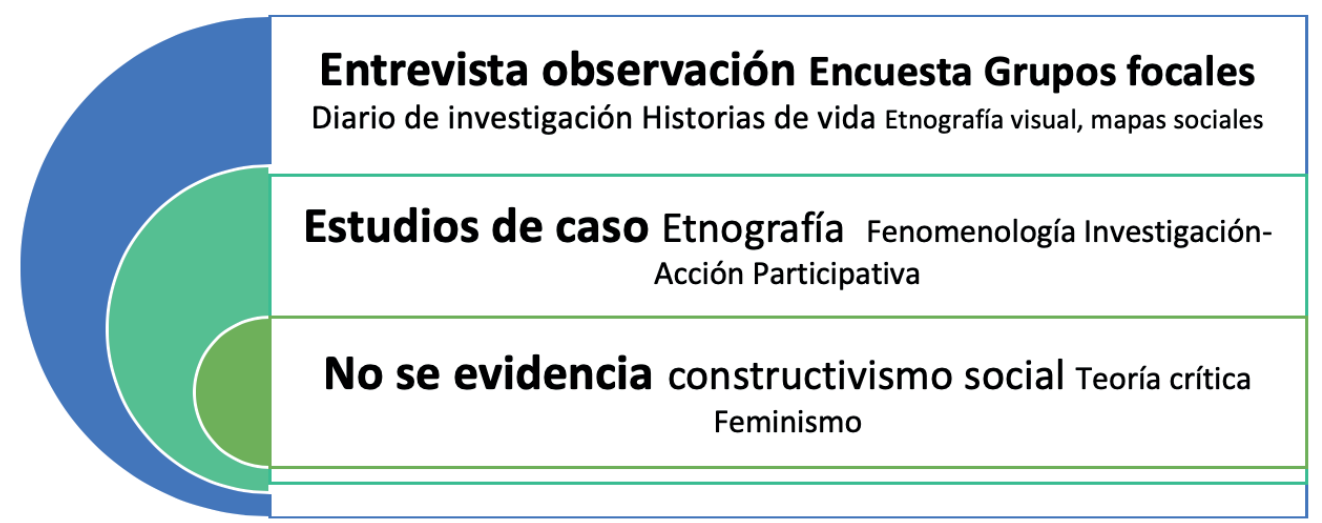

Fuente: Elaborada por las autoras

\section{El paradigma de investigación}

El paradigma de investigación es descrito como el conjunto de creencias que definen el modo de entender el mundo del investigador (Guba y Lincoln, 1994). Es decir, el paradigma de investigación son los lentes a través de los cuales el investigador observa el mundo y que, por lo tanto, influirá en su modo de observar su objeto de investigación. Para varios autores, el investigador deberá posicionar, de manera fundamentada su paradigma en alguno de las siguientes opciones: positivismo y postpositivismo, constructivismo social y teoría critica (Wolgemuth et al. 2015). La principal diferencia entre las opciones señaladas es que, mientras las posiciones positivista y postpositivista consideran que hay una sola verdad absoluta y una única manera de alcanzar el conocimiento, el constructivismo y la teoría crítica creen que existen diversas verdades y conocimientos que son socialmente construidos, y para los cuales existen diversos modos de llegar (Hays y Singh, 2012, p. 40). Es importante reiterar que la teoría crítica, además de creer en una realidad socialmente construida, evidencia las relaciones de poder y promueve la emancipación de los grupos históricamente subyugados mediante el proceso investigativo.

En el análisis de los documentos, se evidenció que solo seis de los 21 documentos describen el paradigma de investigación utilizado en el estudio. En la Figura 6, esta situación se subraya con la expresión 'no se evidencia'. El constructivismo social aparece como el más utilizado en estos seis documentos. La lectura de los argumentos que fundamenta 
la utilización del constructivismo social en estos documentos muestra que los investigadores reconocen la necesidad de incluir las voces de los diversos actores que son parte de la relación entre turismo y comunidad, además, reconocen la diversidad cultural que existe en América Latina. Temas como la inequidad de género, la situación actual del indígena en la sociedad, así como la exclusión y discriminación de las comunidades campesinas son evidenciados mediante la utilización del constructivismo social.

\section{Tradiciones de investigación}

De acuerdo a Hays y Singh (2012), una vez que el paradigma de investigación ha sido definido, el siguiente paso es identificar la tradición de investigación, que puede llevar a la práctica los principios del paradigma escogido. Estas autoras clasifican en cinco los grupos de tradiciones de investigación cualitativa, los cuales se describen en el siguiente párrafo:

1. la tradición universal (estudio de caso), 2) la experiencia y la formulación de la teoría (teoría fundamentada, la fenomenología, la investigación heurística, y la investigación cualitativa consensual); 3) simbolismo (interacción simbólica, la semiótica, la hermenéutica, la narratología e historias de vida); 4) las expresiones culturales del proceso y la experiencia (la etnografía, la etnometodología, auto-etnografía), y 5) la investigación como un agente de cambio (investigación-acción participativa) (Hays y Singh, 2012, p. 66).

En la Figura 6, se evidencia que el estudio de caso y la etnografía fueron las tradiciones de investigación preferidas entre los autores de los artículos analizados. El estudio de caso es definido como un hecho, acción o proceso bien delimitado que se caracteriza por una singularidad que lo hace único; los estudios de caso pueden ser singulares o múltiples (Yin, 2009, p. 46). Varios de los artículos analizados reportan la aplicación de estudio de casos múltiples con el fin de identificar patrones, tendencias y hacer comparaciones. En el caso de la etnografía, esta es una tradición de investigación que permite al investigador describir, analizar, e interpretar las dinámicas culturales de un grupo o sistema social (Creswell, 2013). Los artículos analizados que utilizaron el método etnográfico se enfocaron en cómo la comunidad interpreta y da sentido a las relaciones sociales y a las relaciones con la naturaleza, y cómo estas relaciones se ven afectadas cuando el turismo ingresa en la comunidad.

\section{Los métodos de recolección de información}

Varios autores recomiendan que el método de recolección de datos debe necesariamente vincularse con la lógica del paradigma y tradición de investigación, así como con el contexto donde se aplicará el estudio, y además considerar la dinámica de la relación entre el investigador y el objeto de estudio (Creswell, 2013; Hays y Singh, 2012). En la revisión de la metodología de los documentos analizados se identifica que la mayoría de los estudios reportan el uso de entrevistas, observación participante, grupos focales y encuestas como herramientas preferidas para el levantamiento de información en las comunidades estudiadas.

Los autores que utilizaron la entrevista procuraron identificar actores clave para aplicar esta herramienta. La técnica 'bola de nieve' les permitió ir generando una red de contactos basada en referencias. En el caso de los autores afiliados en instituciones de países desarrollados, el uso de la técnica de bola de nieve y entrevistas con actores claves les permitió acceder al territorio de estudio de una manera más efectiva. El principal reto que los autores 
reportan en la aplicación de las entrevistas es la barrera idiomática entre el entrevistador y el entrevistado. Los estudios de Lupoli et al. (2014; 2015), y de Kuo (2008) proponen la contratación de un traductor para el trabajo en campo o una prueba piloto como estrategias para afinar instrumentos de recolección de datos cuando el investigador no habla el mismo idioma que la comunidad estudiada.

La observación es considerada una de las herramientas más frecuentes entre los estudios de caso y etnografías (Campos y Lule, 2012). Esta tendencia se reflejó en los casos analizados, ya que un importante número de autores utilizaron este método. Para estos autores, la observación les permitió conocer aspectos del fenómeno estudiado que muchas veces no se evidencian en las entrevistas.

Para varios autores, la ventaja del grupo focal como método de recolección de datos es que permite conocer más de cerca el tipo de interacciones, diálogos y posibles conflictos que se generan dentro de una comunidad u organización (Colucci, 2007; Lambert y Loiselle, 2008). En varios de los casos analizados, los investigadores utilizaron los grupos focales para introducir el proyecto de investigación en la comunidad participante, así como para compartir los resultados de la investigación y recibir una retroalimentación.

El uso de la encuesta como parte de la recolección de datos ha sido justificado, especialmente, cuando existe un gran número de participantes y se tiene poco tiempo para levantar la información en el campo (Creswell, 2013). El análisis de los artículos evidenció que quienes prefirieron utilizar las encuestas fueron los investigadores que pertenecen a instituciones afiliadas al Norte Global. Es posible que la barrera idiomática entre investigador y comunidad, así como el limitado tiempo para el estudio hagan de la encuesta la herramienta de recolección más efectiva. Fue interesante observar que varios de los autores que utilizaron la encuesta para levantar información procuraron realizar una fase de aplicación piloto. También se debe destacar que algunos de los investigadores reportan la contratación de miembros de la comunidad u otros actores cercanos a ella para la aplicación de las encuestas.

En general, se evidencia que la elección de las herramientas de investigación en los estudios analizados responde no solo al paradigma y tradición de investigación, sino también al contexto, y factores como tiempo y barreras idiomáticas.

\section{Validez de la información y subjetividades}

Como se señaló en la parte introductoria, la investigación cualitativa y mixta del turismo comunitario requiere que los investigadores asuman nuevos roles. Estos roles demandan alta reflexividad y perspectivas críticas, así como estrategias para minimizar subjetividades. Varios autores sugieren la aplicación de estrategias para aumentar la reflexión crítica y reducir las subjetividades durante el proceso de investigación (Lincoln y Guba, 1985; Goodson y Philimore, 2004). Algunas de estas estrategias son la triangulación, la permanencia prolongada en el campo por parte del investigador, la utilización de un diario de investigación y la verificación de la información por parte de pares y comunidades participantes.

La triangulación implica el uso de múltiples formas de recolección de datos o la participación de múltiples autores en el proceso de investigación para comparar la información e incrementar la credibilidad de los resultados (Hays y Singh, 2012; Creswell, 2013). En la mayoría de los estudios analizados, los autores utilizan al menos una técnica de triangulación de la información. La técnica preferida es la combinación de múltiples herramientas de levantamiento de información (observación y entrevistas, encuestas, entrevistas y grupos focales) para comparar los resultados. 
La permanencia prolongada en la zona de estudio fue otra de las estrategias para incrementar la validez de la información, especialmente cuando se utilizó la etnografía como tradición de investigación. En once de los artículos revisados, se reportan permanencias en el campo por más de doce meses. Estos autores argumentan que una mayor permanencia en la zona les permitió entender de mejor manera la dinámica de la relación entre turismo y comunidad.

El diario de campo es una herramienta bastante utilizada para fortalecer la confiabilidad de la información en la investigación cualitativa. Sumara (1996) describe al diario de campo como el espacio donde el investigador anota las experiencias, sentimientos y hechos que emergen cotidianamente en el trabajo de campo y que sirven como soporte y complemento de las otras herramientas que se están utilizando. Únicamente, dos de los artículos analizados resaltan los beneficios que el uso de un diario de campo trajo para la recolección y análisis de los resultados (Duffy et al., 2012; Trejos y Chian, 2009).

Finalmente, la participación de los miembros de la comunidad como revisores y proveedores de retroalimentación se considera una herramienta válida para incrementar la confiabilidad de la información y, sirve para democratizar la información de la investigación. Varios autores argumentan que esta estrategia es la más recomendada para establecer validez y credibilidad en la investigación cualitativa (Lincoln y Guba, 1985; Datta et al. 2015). De los documentos analizados, únicamente Lupoli et al. $(2014,2015)$ reportan una permanente socialización y retroalimentación de la información con los participantes. Estos autores utilizaron varias reuniones y la socialización del proceso de la investigación y resultados en resúmenes.

\section{DISCUSIÓN}

\section{La injusticia cognitiva en el contexto del turismo comunitario}

Siguiendo a Boaventura de Sousa Santos (2011), para superar la "injusticia cognitiva" en el Sur es necesario la generación de conocimientos desde las voces de los países y comunidades que han sido históricamente empobrecidos. Solo entonces, se podría generar un conocimiento adecuado al contexto y realidades de estas comunidades y contribuir a una mejor calidad de vida para ellos. El análisis realizado en el presente documento sobre los estudios del turismo comunitario durante los años 2000 a 2015, que es conocido como el tiempo en el que se impulsó al turismo como una herramienta para reducir la pobreza entre las comunidades empobrecidas del Sur Global, evidencia que la dinámica de estos estudios no ha contribuido a cerrar la brecha de "injusticia cognitiva" entre Norte y Sur. En cuanto a la producción del conocimiento sobre turismo comunitario en el Sur, los resultados de la Figura 2 evidencian una dinámica en la que el Norte es el que investiga, y el Sur es el investigado. Un problema típico en las geopolíticas del conocimiento, en general (Walsh, 2003; de Sousa Santos, 2011), y, de manera específica también en los estudios de turismo y desarrollo (Hannam, 2002; Kobasi citado en Tribe, 2004; Nielsen y Wilson, 2012).

La distribución del conocimiento científico sobre turismo comunitario también presenta falencias en cuanto a la accesibilidad de esta información por parte de las comunidades del Sur. La Figura 5 muestra como el $92 \%$ de las publicaciones que reportan investigaciones en turismo comunitario requieren un pago para acceder a esta información. Mientras que la Figura 4 muestra como el $95 \%$ de estos artículos están publicados en el idioma inglés. Considerando que las comunidades indígenas y campesinas de las zonas rurales de Améri- 
ca Latina y África han sido las principales regiones donde se ha promovido el turismo como una alternativa para la aliviar la pobreza (UNWTO, 2017) es preocupante que la información sobre turismo comunitario tenga barreras idiomáticas y económicas para su acceso. La información científica en turismo es clave para tomar decisiones tanto a nivel comunitario como para las políticas públicas en turismo a nivel local y nacional. En el caso específico de América Latina, el índice del dominio del idioma inglés es bajo o muy bajo, situación que no es solo exclusiva de las comunidades rurales sino también de quienes habitan en las zonas urbanas (English First, 2018), esto quiere decir que idiomáticamente los artículos revisados serán inaccesibles no solo para las comunidades anfitrionas, sino muy posiblemente también para los hacedores de políticas. Las barreras idiomáticas también pueden afectar a los investigadores locales para quienes el idioma ingles no sea su lengua nativa, o que tengan un índice de dominio bajo. De acuerdo con varios autores el protagonismo del idioma inglés como lengua internacional de comunicación científica es un limitante para la democratización de los espacios científicos para varios académicos alrededor del mundo (Ferguson, 2007; Meneghini y Packer, 2007; Shum y Pico, 2016).

La crítica que se genera en este estudio no busca desvalorizar la importante contribución que los académicos del Norte Global hacen al crear conocimientos sobre turismo comunitario del Sur, sino que llama la atención para que este conocimiento sea accesible y comprensible para las comunidades anfitrionas del turismo, los hacedores de políticas públicas y los investigadores locales. Estos actores requieren que los artículos científicos generados en este tema se publiquen en un idioma comprensible para ellos y que sean de acceso libre, pudiendo así la información contenida en ellos, ser utilizada para la toma de decisiones sobre el desarrollo del turismo en sus territorios. El protagonismo de las Ciencias Sociales como el área de estudio donde se producen en mayor parte los estudios sobre turismo comunitario (ver Figura 3) representa una esperanza para que se dé más cabida a propuestas investigativas interdisciplinarias, que vayan más allá de lo económico, y que propongan espacios más democráticos en la producción y distribución del conocimiento.

\section{Diseños de investigación integrales y reflexivos}

La dinámica de los diseños de investigación utilizados en los 21 artículos analizados evidencia una creciente tendencia en aplicar metodologías cualitativas y mixtas para el estudio del turismo comunitario. Sin embargo, el nivel de reflexión fue escaso sobre los paradigmas de investigación que influyen en el pensamiento de los autores. Varios autores argumentan que evidenciar los paradigmas de investigación en los estudios de turismo es una tarea ética y necesaria (Goodson y Philimore, 2004; Ryan, 2005). Por ejemplo, si el investigador utiliza un enfoque positivista en el que prioriza lo cuantitativo debería enfatizar que se estudia solo una dimensión del turismo y que, por lo tanto, no se podrían generalizar los resultados como ciertos para todo el fenómeno de estudio.

Esta necesidad de evidenciar el paradigma de investigación se vuelve crítica en los estudios del turismo en el Sur Global. La primera parte de esta investigación evidenció que la producción y difusión del conocimiento en turismo comunitario está concentrada en el Norte Global. Las realidades, culturas investigativas y modos en cómo el Norte observa al Sur, en cierto modo, influirán en los diseños de investigación (Hannam, 2002; Nielsen y Wilson, 2012). Pero esta necesidad de evidenciar el paradigma de investigación es válida también para investigadores afiliados a instituciones del Sur, ya que en su gran mayoría no comparten modos de vida o la cultura de las comunidades indígenas o campesinas que hacen el 
turismo comunitario. Por ejemplo, un investigador no indígena puede obviar elementos de la cosmovisión indígena que influyen en el modo de hacer turismo comunitario por considerar estos elementos como no válidos dentro del conocimiento científico.

\section{CONCLUSIONES}

El análisis del perfil de las investigaciones y sus autores, en cuanto a la producción de conocimiento sobre turismo comunitario en el Sur Global en general, y en América Latina en particular, evidencia que la producción académica en ese tema está concentrada principalmente en el Norte Global. Se identificó también que la gran mayoría de artículos científicos sobre este tema están publicados en el idioma inglés y que se requiere un pago o suscripción para su acceso. Esta situación hace que este conocimiento científico se vuelva inaccesible para las comunidades anfitrionas hacedores de políticas públicas e investigadores locales que, en su mayoría, no dominan el idioma inglés y no cuentan con los recursos económicos para la descarga de estos artículos.

El análisis del contenido de los 21 artículos sobre turismo comunitario en el contexto de América Latina resalta el interés creciente que existe entre los académicos para utilizar métodos cualitativos y mixtos (cualitativos y cuantitativos) en sus investigaciones. Los diseños de investigación de estos artículos mostraron una diversidad de estrategias metodológicas para una comprensión más integral del fenómeno de estudio y su contexto. El estudio de caso y la etnografía fueron las tradiciones de investigación más utilizadas entre los artículos analizados. En cuanto a las herramientas de recolección de datos, la entrevista y la observación de campo fueron las estrategias más utilizadas en estos estudios. En cuanto al paradigma de investigación, fueron muy pocos los autores que evidenciaron sus paradigmas de investigación y cómo sus modos de entender el mundo influyeron en sus diseños de investigación.

La validez de la información y la reducción de subjetividades son tareas necesarias para quienes utilizan enfoques cualitativos y mixtos. En los estudios analizados, la triangulación de la información fue la estrategia más utilizada durante el proceso investigativo, lo que se evidenció en el uso de múltiples herramientas para la recolección de datos y múltiples informantes.

Los resultados de este estudio son una contribución al desarrollo de investigaciones sobre turismo comunitario, especialmente desde el pensamiento de autores afiliados a instituciones del Sur Global. La visualización de las brechas de acceso a la información científica entre el Norte y Sur, las múltiples dimensiones de la relación entre turismo, comunidad y pobreza, y un rol más crítico y reflexivo por parte de los investigadores son los tres elementos que recomendamos se tomen en cuenta en futuras investigaciones. Además, consideramos que para desarrollar procesos de investigación más integrales y participativos son necesarios enfoques de investigación interdisciplinaria, cooperación académica entre autores del Norte y Sur, y una mayor inclusión de las comunidades participantes como sujetos activos en el proceso de la investigación.

\section{REFERENCIAS}

Brenner, L., y Vargas-del-Río, D. (2013). Community-based ecotourism and environmental protection in Mexico: a synergetic strategy or trendy slogan. Tourism and Developments-Issues and Challenges, 255-284.

Campos, G., y Lule, N. (2012). La observación, un método para el estudio de la realidad. Xihmai, $7(13), 45-60$. 
Cañada, E. y Gascón, J. (2007). Turismo y desarrollo: Herramientas para una mirada crítica. Managua: Fundacion Luciernaga.

Carpentier, J. (2014). Los achuar y el ecoturismo: ¿ una estrategia sostenible para un desarrollo autónomo?. Bulletin de l'Institut français d'études andines, 43 (1)), 133-158.

Carr, A., Ruhanen, L., y Whitford, M. (2016). Indigenous peoples and tourism: the challenges and opportunities for sustainable tourism. Journal of Sustainable Tourism, 24(8-9), 1067-1079.

Colucci, E. (2007). "Focus groups can be fun": The use of activity-oriented questions in focus group discussions. Qualitative health research, 17(10), 1422-1433.

Creswell, J. (2013). Qualitative inquiry and research design: Choosing among five approaches. Washington, EE. UU.: SAGE.

Datta, R., Khyang, N. U., Prue Khyang, H. K., Prue Kheyang, H. A., Ching Khyang, M., y Chapola, J. (2015). Participatory action research and researcher's responsibilities: an experience with an Indigenous community. International Journal of Social Research Methodology, 18(6), 581-599.

De Sousa Santos, B. (2011). Epistemologías del Sur. Utopía y Praxis Latinoamérica, 16 (54), 17-39. Recuperado de https://www.redalyc.org/pdf/279/27920007003.pdf

Duffy, L. N., Mowatt, R. A., Cnacellor, H. C., y Cárdenas, D. A. (2012). Machismo-marianismo and the involvement of women in a community-based tourism project in Ecuador, South America. Tourism Analysis, 17(6), 791-803.

English First. (2018). Indice del dominio del inglés de EF. Recuperado de https://www.ef.com.co/_/ / media/centralefcom/epi/downloads/full-reports/v8/ef-epi-2018-spanish-latam.pdf

Falconí, F., y Ponce, J. (2011). Ecoturismo: emprendimientos populares como alternativa a un desarrollo excluyente. Espacios en disputa: el turismo en Ecuador, 167-206.

FEPTCE (2007). Manual de Calidad para la Gestión del Turismo Comunitario en Ecuador. Quito, Ecuador: FEPTCE.

Ferguson, G. (2007). The global spread of English, scientific communication and ESP: questions of equity, access and domain loss. Ibérica: Revista de la Asociación Europea de Lenguas para Fines Especificos (AELFE), (13), 7-38.

Fraser, Nancy. 2005. Reframing Justice: In a Globalizing World. New Left Review (36): 69-88.

Gascón, G. G., y Ojeda, D. (2014). Turistas y campesinado: el turismo como vector de cambio de las economías campesinas en la era de la Globalización. Foro de Turismo Responsable, PASOS online. Retrieved from http://www.pasosonline.org/Publicados/pasosoedita/PSEdita12.pdf

Gascón, J. (2011). Community-Based Tourism and Peasant Differentiation: Considerations from an Andean case Turismo rural comunitario y diferenciación campesina: Consideraciones a partir de un caso andino. Mundo Agrario, 11(22), Mundo Agrario, 01 January 2011, Vol.11 (22).

Gascón, J. (2013). The limitations of community-based tourism as an instrument of development cooperation: the value of the Social Vocation of the Territory concept. Journal of Sustainable Tourism, 21(5), 716-731

Gascón, J. (2015). Pro-Poor Tourism as a Strategy to Fight Rural Poverty: A Critique. Journal of Agrarian Change, 15(4), 499-518.

Goodson, L., y Phillimore, J. (eds.) (2004). Qualitative research in tourism: Ontologies, epistemologies and methodologies. Nueva York, EE. UU.: Routledge

Gössling, S. (2005). Tourism's contribution to Global environmental change: space, energy, disease and water. Tourism recreation and climate change: International perspectives, $286 \mathrm{e} 300$.

Guba, E. G., y Lincoln, Y. S. (1994). Competing paradigms in qualitative research. En N. K. Denzin y Y. S. Lincoln (eds.), Handbook of qualitative research (105-117). Thousand Oaks, CA: Sage

Hannam, K. (2002). Tourism and development, I: globalization and power. Progress in Development Studies, 2(3), 227-234.

Hays, D. G., y Singh, A. A. (2012). Qualitative Inquiry in Clinical and Educational Settings. Nueva York, EE. UU.: The Guilford Press. 
Jamal, T., y Camargo, B. A. (2014). Sustainable tourism, justice and an ethic of care: Toward the just destination. Journal of Sustainable Tourism, 22(1), 11-30.

Kuo, E. (2008). Community Impacts of Ecotourism: A Case-study of a Women's Artisan Cooperative in Monteverde, Costa Rica.

Lambert, S. D., y Loiselle, C. G. (2008). Combining individual interviews and focus groups to enhance data richness. Journal of Advanced Nursing, 62, 228-237.

Lincoln, Y. S. y Guba, E. G. (1985). Naturalistic inquiry. Beverly Hills, CA: Sage.

Lupoli, C. A., Morse, W. C., Bailey, C., y Schelhas, J. (2014). Assessing the impacts of international volunteer tourism in host communities: a new approach to organizing and prioritizing indicators. Journal of Sustainable Tourism, 22(6), 898-921.

Lupoli, C. A., Morse, W. C., Bailey, C., y Schelhas, J. (2015). Indicator development methodology for volunteer tourism in host communities: creating a low-cost, locally applicable, rapid assessment tool. Journal of Sustainable Tourism, 23(5), 726-747.

Lyall, A. (2011). Estado y turismo comunitario en la sierra. In M. Prieto (Ed.), Espacios en disputa: el turismo en Ecuador (65-98). Quito, Ecuador: FLACSO Ecuador.

Matarrita-Cascante, D., Brennan, M. A., y Luloff, A. E. (2010). Community agency and sustainable tourism development: The case of La Fortuna, Costa Rica. Journal of

Sustainable Tourism, 18(6), 735-756. Mitchell, R. E., y Eagles, P. F. (2001). An integrative approach to tourism: Lessons from the Andes of Peru. Journal of Sustainable Tourism, 9(1), 4-28.

Meneghini, R., y Packer, A. L. (2007). Is there science beyond English?: Initiatives to increase the quality and visibility of non-English publications might help to break down language barriers in scientific communication. EMBO reports, 8(2), 112-116.

Mitchell, R. E., y Eagles, P. F. (2001). An integrative approach to tourism: Lessons from the Andes of Peru. Journal of Sustainable Tourism, 9(1), 4-28.

Mitchell, R. E., y Reid, D. G. (2001). Community integration: Island tourism in Peru. Annals of tourism research, 28(1), 113-139.

Mowforth, M., y Munt, I. (2015). Tourism and sustainability: Development, Globalization and new tourism in the third world. Routledge.

Nielsen, N., y Wilson, E. (2012). From invisible to indigenous-driven: A critical typology of research in indigenous tourism. Journal of Hospitality and Tourism Management, 19(1), 67-75.

Pereiro, X., y De León, C. (2007). Los impactos del turismo en Kuna Yala (Panamá). Turismo y cultura entre los Kuna de Panamá. Ramón Areces.

Ruiz-Ballesteros, E. (2011). Social-ecological resilience and community-based tourism: an approach from Agua Blanca, Ecuador. Tourism Management, 32(3), 655-666.

Ruiz-Ballesteros, E., y Brondizio, E. (2013). Building negotiated agreement: The emergence of community-based tourism in Floreana (Galapagos Islands). Human Organization, 72(4), 323-335.

Ruiz-Ballesteros, E., y Gual, M. A. (2012). The emergence of new commons. Human ecology, 40(6), 847-862

Ruiz-Ballesteros, E., Hernández, M., Coca, A., Cantero, P., y Del Campo, A. (2008). Turismo comunitario en Ecuador. Comprendiendo el community-based tourism desde la comunidad. Pasos. Revista de turismo y patrimonio cultural, 6(3), 399-418.

Ryan, C. (2005). Ethics in tourism research: objectivities and personal perspectives. Tourism research methods: Integrating theory with practice, 9-19.

Santafe, V. (2012). Turismo comunitario e interculturalidad: Una mirada crítica desde la experiencia Tsachila. Quito, Ecuador: FLACSO Ecuador. Recuperado de: https://biblio.flacsoandes.edu. ec/shared/biblio_view.php?bibid=135467ytab=opac

Shum, G. y Pico, T. (2016). ¿Tiene que ser el inglés la lengua dominante de la ciencia? Recuperado de https://www.scientificamerican.com/espanol/noticias/tiene-que-ser-el-ingles-la-lenguadominante-de-la-ciencia/

Spenceley, A., y Meyer, D. (2012). Tourism and poverty reduction: Theory and practice in less economically developed countries. Journal of Sustainable Tourism, 20(3), 297-317. 
Sumara, D. J. (1996). Using commonplace books in curriculum studies. JCT Journal of Curriculum Theorizing, 12, 45-48.

Torres, L. y Ruiz-Ballesteros, E. (2009). Estrategia metodológica para el estudio del turismo comunitario. En E. Ruiz-Ballesteros y M. Vintimilla (Coords), Cultura, comunidad y turismo: Ensayos sobre el turismo comunitario en el Ecuador (19-40). Quito, EC: Abya-Yala.

Trejos, B., y Chiang, L. H. N. (2009). Local economic linkages to community-based tourism in rural Costa Rica. Singapore Journal of Tropical Geography, 30(3), 373-387.

Tribe, J. (2004). Knowing about tourism. En J. Philimore, y L. Goodson (eds.), Qualitative Research in Tourism (46-62). New York, EE. UU.: Routledge.

Tsao, C. Y., y Ni, C. C. (2016). Vulnerability, resilience, and the adaptive cycle in a crisis-prone tourism community. Tourism Geographies, 18(1), 80-105.

UNWTO- United Nations World Tourism Organization (2017). Making tourism a tool to fight poverty: ten years of the ST-EP initiative. Retrieved from: http://cf.cdn.unwto.org/sites/all/files/pdf/ brochure_st-ep_web.pdf

Walsh, C. (2003). Las geopolíticas del conocimiento y colonialidad del poder. Entrevista a Walter Mignolo. Polis. Revista Latinoamericana (4), 1-22.

Wolgemuth, J. R., Erdil-Moody, Z., Opsal, T., Cross, J. E., Kaanta, T., Dickmann, E. M., y Colomer, S. (2015). Participants' experiences of the qualitative interview: Considering the importance of research paradigms. Qualitative Research, 15(3), 351-372.

Yin, R. (2009). Case study research: Design and methods. Thousand Oaks, CA: SAGE.

Zapata, M. J., Hall, C. M., Lindo, P., y Vanderschaeghe, M. (2011). Can community-based tourism contribute to development and poverty alleviation? Lessons from Nicaragua. Current Issues in Tourism, 14(8), 725-749. 